Ensino, Saúde e Ambiente - V 7 (1), Edição Especial, maio de 2014

\title{
O CARAMUJO AFRICANO (aChatina FULICA), PERIGOS PARA A SAÚdE E O MEIO AMBIENTE: UMA PROPOSTA DE ALFABETIZAÇÃO ECOLÓGICA
}

\section{THE GIANT AFRICAN LAND SNAIL (ACHATINA FULICA) DANGERS FOR HEALTH AND ENVIRONMENT: A PROPOSAL FOR ECOLOGIC LITERACY}

\author{
Ricardo Moreira de Queiroz ${ }^{1}$, Augusto Fachín Terán ${ }^{2}$, Andrea Garcia de Queiroz ${ }^{3}$ \\ ${ }^{1}$ Professor Mestre e integrante do Grupo de Estudo e Pesquisa Educação em Ciências em espaços não \\ formais - GEPECENF - (UEA), Brasil, ricardomdequeiroz@ hotmail.com.br \\ ${ }^{2}$ Professor Doutor do Programa de Pós-Graduação em Educação e Ensino de Ciências na Amazônia \\ (UEA), Brasil, fachinteran@yahoo.com.br \\ ${ }^{3}$ Mestranda do Curso de Educação em Ciências na Amazônia (UEA), Bolsista da FAPEAM, Brasil, \\ andrea_agq@hotmail.com
}

\begin{abstract}
RESUMO
A educação é uma importante ferramenta para entender as causas e as consequências sobre a inserção de espécies exóticas em ambientes naturais, bem como os problemas que esta ação causa ao meio ambiente e a sociedade. Este artigo busca desenvolver um diálogo com os leitores sobre a inserção de animais exóticos e os perigos para a saúde e os ecossistemas, sugerindo uma proposta de alfabetização ecológica com o tema dos animais exóticos. Os sujeitos da pesquisa foram alunos do $4^{\circ}$ e $5^{\circ}$ ano de Ensino Fundamental de uma escola da zona centro sul da cidade de Manaus, Amazonas. A mudança de postura frente à problemática dos organismos invasores e o reconhecimento de nossas ações cotidianas enquanto educadores e contribuintes na formação de sujeitos críticos e reflexivos resultam no constructo dos primeiros alicerces de uma Alfabetização Ecológica.
\end{abstract}

Palavras-chave: Caramujo africano, Achatina fulica, espécies exóticas, alfabetização ecológica, Amazônia.

\begin{abstract}
Education is an important tool that aids to understand causes and consequences about introducing exotic species in nature, as well as the effects on environment and society. This article aims to dialogue with the readers about introducing exotic species and dangers for health and environment, presenting a proposal for literacy in ecology with topics about exotic animal. Investigation subjects were $4^{\text {th }}$ and $5^{\text {th }}$ grade students from an Elementary School located in southern center area in Manaus city, Amazonas State. Our stand on problems about invader organisms and perceiving our actions as educators and facilitators on education of critical and reflexive subjects resulting in the first bases of ecologic literacy.
\end{abstract}

Keyword: Giant African land snail, Achatina fulica, exotic species, ecologic literacy, Amazon.

\section{INTRODUÇÃO}

Atualmente, as questões relacionadas à ecologia e perda da biodiversidade tem sido protagonista de diversos debates. Ambientalistas de diversas partes do planeta tem Edição Especial com os melhores trabalhos apresentados no IV ENECiências: UFF - 13 a 16 de maio de 2014. 


\section{Ensino, Saúde e Ambiente - V 7 (1), Edição Especial, maio de 2014}

se juntado com o propósito de lutar em pro da preservação e conservação dos recursos naturais, combatendo a ideia de que estes são ilimitados, e opondo-se ao capitalismo exagerado.

Na região Amazônica, dentre os muitos problemas relacionados às questões ecológicas, temos a presença de organismos exóticos ou alienígenas. Isto é, a invasão de plantas e animais oriundos de outros ecossistemas, trazendo sérias consequências para as comunidades de plantas e animais nativos, originando o que chamamos de “desequilíbrio ecológico".

Este artigo busca desenvolver um diálogo com os leitores sobre a inserção de animais exóticos e os perigos para a saúde e os ecossistemas, sugerindo uma proposta de alfabetização ecológica com o tema dos animais exóticos.

Dessa forma convidamos todos a um mergulho sobre a ecologia do "caramujo africano" e a problemática à saúde e ao meio ambiente devido à inserção desta espécie no ecossistema amazônico. A continuação, estaremos apresentando uma proposta de alfabetização ecológica, isto é, uma motivação educacional para ampliar a discussão sobre a inserção e os perigos dos animais exóticos.

\section{ANIMAIS EXÓTICOS, O QUE É ISSO?}

A introdução de animais exóticos em um dado ambiente é assunto delicado, e que merece muita atenção. O manejo inadequado, a incapacidade de controlar a espécie e a sua reprodução podem ser desastrosos, levando a formação de grandes pragas agrícolas e/ou urbanas, assim como o desequilíbrio e a competição com espécies nativas (SILVA, OLIVEIRA \& NAVARRO, 2007, p.01). É sabido que este processo de inserção acontece desde muito tempo atrás, visto que as pessoas não sabiam do perigo que estas poderiam causar a sua região. Contudo, hoje sabemos que eles se deslocam e substituem espécies nativas, alteram os ambientes e causam impactos em ciclos ecológicos, além de competir por espaço e alimento com as espécies nativas.

A inserção de aninais exóticos no ecossistema é uma grande ameaça à biodiversidade e está diretamente correlacionada a extinção de espécies podendo causar uma série de prejuízos ambientais, econômicos e à saúde humana. É importante lembrar que todos os seres, incluindo os humanos, estão interconectados e dependem uns dos 
outros (como na cadeia alimentar, por exemplo). Pivello (2011) contribui a respeito do processo de invasão biológica em um ecossistema:

O processo de invasão biológica pode ser dividido em quatro fases distintas: a chegada (ou introdução) da espécie, seu estabelecimento (ou fixação), sua expansão e o equilíbrio da espécie na comunidade. $\mathrm{Na}$ grande maioria dos casos esse equilíbrio se dá com uma grande dominância da espécie invasora na comunidade, levando a uma condição ecologicamente inferior à original, com perda de biodiversidade no nível de espécies e de processos ecológicos.

O processo de introdução de espécies nem sempre ocorre de forma intencional, isto é, pode ocorrer de forma acidental, contribui neste sentido Ricklets:

Nos últimos 200 anos, a América do Norte recebeu mais de 70 espécies não nativas de peixes, 80 de moluscos, 2000 de plantas e 2000 de insetos. Essas espécies podem ter chegado acidentalmente - por exemplo, no lastro dos navios - ou terem sido deliberadamente introduzidas para uso em plantações, plantas ornamentais, espécies de caça ou agentes de controle biológico (2010, p. 496).

Neste caso é importante colocar que embora a quantidade de espécies introduzidas seja significativamente alta, nem sempre estes animais conseguem se adaptar ao novo ambiente, devido ao clima, solo e outros fatores.

\section{HISTÓRICO DA INSERÇÃO DO “CARAMUJO AFRICANO” NO BRASIL}

Segundo Paiva (apud SOUZA, ALVES \& ALVES, 2006, p.82) o A. fulica, é uma espécie oriunda do continente Africano que foi implantada na região do Paraná, por volta de 1980, com o intuito de comercialização de "escargots". A intenção inicial dos produtores da região do Paraná era utilizá-lo na gastronomia como sucessor do gênero Helix, caracóis europeus usados na gastronomia. Porém a espécie importada não teve aceitação pelo público consumidor devido ao gosto que não se assemelhava ao “escargots" do gênero Helix, tal como afirma Rodrigues, Junior \& Monteiro (2007, p.02) “[...] No entanto, com a verificação do fracasso comercial desta iniciativa, e por falta de informação, produtores soltaram os Caramujos no ambiente, o que gerou uma crescente proliferação no território brasileiro". Em alguns lugares o Achatina tem sido criado como isca para pesca em pesqueiros comerciais. Sua propagação ocorre involuntariamente em meio as cargas de trens e caminhões entre outros meios. Atualmente no Brasil está presente em 24 dos 26 estados brasileiros, não se encontrando apenas no Acre e no Amapá. 


\section{Ensino, Saúde e Ambiente - V 7 (1), Edição Especial, maio de 2014}

Seu processo de introdução no Brasil ocorreu pelo menos em três momentos. Duas dessas com o propósito de criação e comercialização, uma em 1989 em Curitiba, outra em 1996 - 1998 em Santos, São Paulo (Teles \& Fontes apud Zanol, 2010, p. 448). A terceira apresenta informações menos precisas onde um morador de Juiz de Fora relata ter comprado matizes de A. fulica em uma feira livre (Barçante apud Zanol, 2010, p.448).

Segundo Paiva (2004) estes animais se alastraram por quase todo o Brasil, estabelecendo populações em vida livre se tornando uma praga agrícola, especialmente na parte litorânea do país. São animais que atacam e destroem plantações tanto de subsistência quanto de fins comerciais na agricultura. Produtores brasileiros de "escargot" importaram o A. fulica sem se importar com os possíveis danos que esta espécie poderia causar no meio ambiente e até mesmo, para a saúde pública se os mesmos fugissem do seu controle.

Nos diversos países em que foi introduzido pelo homem, A. fulica tornou-se uma praga exigindo grande esforço da comunidade local para o extermínio desta espécie, e em muitos destes casos, as ações tomadas para conter o seu avanço geralmente foi sem sucesso. Em alguns países asiáticos a espécie ainda continua sua devastação.

\section{PERIGOS QUE O ACHATINA FULICA PODE TRAZER A UM ECOSSISTEMA}

A introdução de A. fulica em determinada região pode levá-la a ser considerada invasora, ocupando o espaço de espécies nativas e alterando o ecossistema, devido a fatores como sua grande capacidade reprodutiva, ausência de predadores naturais, adaptabilidade climática e recursos variados. O processo de introdução e adaptação de espécies estranhas a um determinado ecossistema é chamado de contaminação biológica ou poluição biológica. Estas espécies além de competirem por espaço e alimento com as espécies nativas também podem interferir prejudicialmente na vida e na saúde dos seres humanos.

Paiva (2004) diz que a introdução de espécies exóticas em outro ecossistema, favorecerá este animal a se tornar uma praga agrícola, contribui neste sentido: “[...] em muitos países os próprios "escargots" (Helix spp.) tiveram a criação e importação proibida pela possibilidade de se tornarem importante praga agrícola, especialmente em hortas (Canadá e Estados Unidos, por exemplo)”.

Edição Especial com os melhores trabalhos apresentados no IV ENECiências: UFF - 13 a 16 de maio de 2014. 


\section{Ensino, Saúde e Ambiente - V 7 (1), Edição Especial, maio de 2014}

A. fulica apesar de desprovido de sistema de defesa, é basicamente protegido pela natureza e consegue se camuflar no ambiente pela sua cor que se confunde com as folhagens secas, passando despercebido por outros animais. Suas características são: concha, que protege o animal e tem forma helicoidal ou espiralada, de cor marrom; manto, que recobre o animal em toda sua extensão da concha e é regenerativa em casos de acidentes com o animal; corpo, (cabeça, pé, tronco e massa visceral) é formado de água, lipídios, sais minerais e proteínas (FERRAZ, 1999).

O Achatina em seu tamanho adulto pode alcançar até $15 \mathrm{~cm}$ de comprimento de concha e pesar mais de 200g. É uma espécie parcialmente arborícola, isto é, pode se alimentar sobre as árvores e escalar edificações e muros. É extremamente prolífica, de 50 a 400 ovos por desova. Seus ovos são de cor branca e ficam enterrados na terra, possuem aproximadamente 5-6 $\mathrm{mm}$ de comprimento por 4-5 $\mathrm{mm}$ de largura.

Alimenta-se de folhas, flores e frutos de muitas espécies, sendo mais ativo em regiões com inverno úmido e pouco frio. Resiste ao período de seca e ao frio hibernal. Pode viver em florestas e capoeiras, bordas de florestas, caatingas, brejos, áreas de vegetação nativa, horta, terrenos baldios, quintais e jardins.

Segundo Paiva apud Eston et al (2006) o “caramujo africano" está entre as 100 principais espécies invasoras do mundo. A possibilidade de adaptação a diversos ambientes e a rapidez do processo de reprodução tornam-na uma ameaça à biodiversidade amazônica.

\section{OS PERIGOS DO ACHATINA FULICA À SAÚDE}

Segundo Coelho (2005, p.8) o “caramujo africano" “é uma espécie voraz podendo se alimentar de cerca de 500 tipos de plantas", muitos dos quais são usados pelos humanos na sua alimentação. Esta espécie é facilmente encontrada hoje nos inúmeros terrenos baldios que existem em Manaus de preferência próximo aos igarapés e locais onde a comunidade costuma jogar lixos domésticos o que pode servir de alimentação também a espécie. Segundo dados revelados pela Diretora de Vigilância em Saúde da SEMSA em entrevista ${ }^{1}$ ao Jornal do Amazonas sobre os terrenos baldios existentes em Manaus, existem cerca de 2.187 terrenos baldios abandonados por seus

\footnotetext{
${ }^{1}$ Entrevista exibida no dia 15 de janeiro de 2013, disponível em: <http://g1.globo.com/am/amazonas/amazoniatv/videos/ttedicoes/v/terrenos-baldios-traz-riscos-a-saude-alerta-secretaria/2346615/>.

Edição Especial com os melhores trabalhos apresentados no IV ENECiências: UFF - 13 a 16 de maio de 2014. 
proprietários. Estes terrenos podem ou não estar servindo de criadouros para esta espécie.

Embora pareça ser um animal inofensivo, este molusco pode ser transmissor de doenças, quando este entra em contato com fatores contaminantes. Conforme Nazareno (2010) abaixo:

\begin{abstract}
Aparentemente o animal não trás dano algum ao ser humano e a natureza. Porém, podem ser vetores de nermatódos e ainda destruir plantações. Quando soltos no ambiente urbano, estes animais entram em contato com vários fatores contaminantes (esgoto, ratos, lixo) representando, portanto, um risco grande a saúde pública, principalmente para crianças que muitas vezes brincam com o animal.
\end{abstract}

No caso do A. fulica, o encontro com esta espécie em vida livre pode causar a transmissão do verme Angiostrongylus cantonensis nematoide causador da Angiostrongilíase meningoencefálica humana. Segundo Vasconcellos e Pile,

A infecção da angiostrogilíase ocorre após o hospedeiro definitivo ingerir as larvas de terceiro estádio (L3) deixadas nos locais por meio de muco produzido pelo molusco. No homem pode apresentar os seguintes sintomas: febre alta, vômito, irritabilidade, rachadura na pele, ausência de reflexos nos tendões, retenção urinária, incontinência anal e meningite, podendo levar crianças à morte. A eosinofilia pode ser constatada no sangue periférico e no líqüor pela citologia. Algumas infecções secundárias bacterianas também podem ser observadas (2001, p.582).

Esta doença pode levar a morte por perfuração intestinal e hemorragia abdominal. Paiva (2004) acrescenta sobre os perigos da inserção do A. fulica em relação a saúde pública:

\footnotetext{
Um dos problemas da introdução de Achatina fulica é que, além de ser transmissor potencial desses vermes, é criado para o consumo, expondo, portanto, a população humana envolvida nessa atividade zootécnicocomercial, bem como usuários, ao risco de contrair as verminoses.
}

A simples manipulação dos caramujos vivos pelas crianças pode causar a contaminação, pois os vermes podem ser encontrados no muco corporal eliminado pelo A. fulica ao se locomover. Contudo Vasconcellos \& Pile (2001) relatam que experimentos realizados para buscar larvas de A. cantonensis em 412 exemplares de $A$. fulica coletados no Vale do Paraíba, Estado do Rio de Janeiro, Brasil, evidenciaram que felizmente em nenhum dos moluscos coletados foi observada eliminação ou presença destas larvas. Mesmo assim os autores nos alertam: 


\title{
Ensino, Saúde e Ambiente - V 7 (1), Edição Especial, maio de 2014
}

\begin{abstract}
Apesar de nenhum caso autóctone de angiostrongilíase ter sido confirmado, a presença de A. fulica não infectado, nos locais coletados, deve ser encarada como preocupante pelas autoridades de saúde pública, já que isso pode estar relacionado à variação sazonal da prevalência do parasita. A presença desses moluscos hospedeiros representa uma possibilidade de instalação da doença na região devido ao frequente trânsito de pessoas, inclusive de nacionalidade estrangeira em busca de trabalho nas indústrias da região, criando ambiente propício ao estabelecimento de um possível foco de transmissão da doença.
\end{abstract}

Vivenciar esta problemática com estudantes do $4^{\circ}$ e $5^{\circ}$ ano de uma escola da zona centro sul da cidade de Manaus - Amazonas nos proporcionou dados bastante interessantes. Ao realizar atividades educativas fora do espaço formal escolar, buscávamos despertar um sentimento de indignação para esta problemática tão próxima a nossas residências e por desconhecermos a gravidade de tal questão, a comunidade acomodou-se a situação. Nesta atividade encontramos diversas conchas do molusco em um terreno baldio, além de evidenciarmos algumas conchas com a presença de água em seu interior. Alguns caramujos africanos após morrer, suas conchas são encontradas com a abertura virada para cima (Figura 1). Dessa forma, ao chegar o período chuvoso (janeiro a maio), acabam por encher de água o que pode servir de criadouro para o mosquito Aedes aegypti. Grande parte desses criadouros fica a disposição por todo o período chuvoso, até que retorne o período da seca, onde poderá secar novamente.

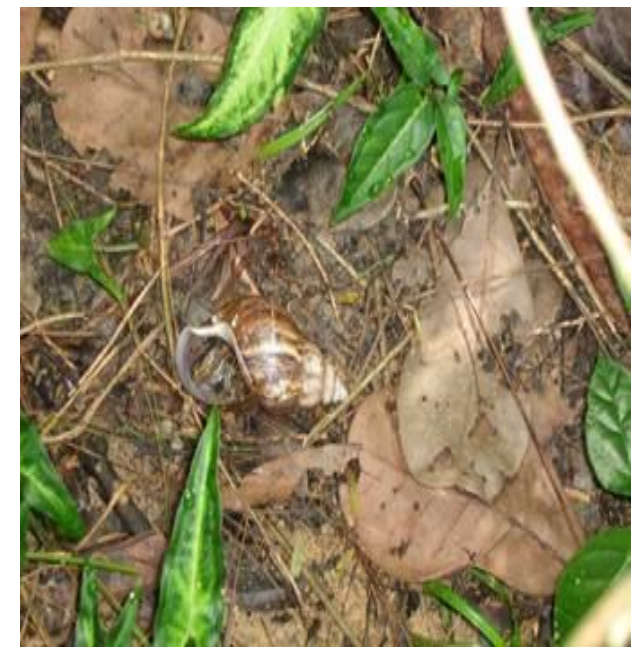

Figura 1: Achatina fulica com a abertura virada para cima. Fonte: QUEIROZ, R.M. 2012.

\section{CONJECTURAS SOBRE OS CARAMUJOS AFRICANOS MORTOS}

Todo dia vivenciamos interações e alterações ecológicas bem diante dos nossos olhos, mas pelo fato de serem constantes, muitas vezes ignoramos aquele fenômeno pelo simples fato daquilo ter se tornado comum. Em algumas práticas realizadas com 


\section{Ensino, Saúde e Ambiente - V 7 (1), Edição Especial, maio de 2014}

estudantes do $4^{\circ}$ e $5^{\circ}$ ano do Ensino Fundamental, por diversos momentos nos defrontamos com indivíduos de "caramujos africanos" mortos em volta de determinada espécie de planta amazônica. Por diversos momentos sempre nos questionamos em uma forma de controlar o avanço desta espécie, assim, numa observação prévia e sem comprovação científica alguma, levantamos a seguinte hipótese: será que os caramujos africanos foram mortos por terem se alimentado e/ou intoxicado com alguma planta amazônica?

\section{ALFABETIZAÇÃO ECOLÓGICA: O TEMA DOS ANIMAIS EXÓTICOS}

A Alfabetização Ecológica é uma teoria que busca criar oportunidades para um relacionamento íntimo do ser humano com o ambiente. Ela teve início no começo deste século e foi inspirada nas ideias e teorias do físico Fritjof Capra e de outros organizadores do Centro de Eco-alfabetização (Center for Ecoliteracy), na Califórnia. A teoria propõe uma ligação na forma de relacionar à sustentabilidade ecológica da sociedade, inspirados nos sistemas naturais e autossustentáveis. (SAMPAIO \& WORTMANN, 2007, p.134).

Segundo Monteiro (2010) a alfabetização que tivemos foi apenas no sentido da escrita e da leitura. Os valores morais antigamente eram de responsabilidade e transmitidos pelas famílias e também pelas religiões. Hoje o ser humano necessita ser alfabetizado ecologicamente, para não perder do todo o seu vínculo maior com a natureza (p.7). Diversos projetos e maneiras de se conhecer a natureza podem ser adequados à educação, entre eles: recuperação de rios, exploração de bacias hidrográficas, arte e poesia, programas de merendas baseados em ingredientes frescos, parcerias entre fazendas e escolas e justiça ambiental urbana.

Por se tratar de um assunto que faz parte do cotidiano dos alunos, o tema animais exóticos poderia ganhar um destaque especial no currículo escolar, visto que, o "caramujo africano" está presente em quase todas as regiões do Brasil. A proposta abarcaria alfabetizar ecologicamente os estudantes sobre o tema "espécies invasoras" e os problemas que estes podem causar às relações ecológicas de um ecossistema. Nesse contexto a utilização de espaços não formais sejam eles institucionalizados ou não, pode se configurar como uma importante ferramenta de reflexão e uma fundamental estratégia, elemento constructo base para formulação dos primeiros passos na busca de uma consciência ecológica. Desta forma os estudantes poderiam analisar a problemática 


\section{Ensino, Saúde e Ambiente - V 7 (1), Edição Especial, maio de 2014}

visitando um ecossistema infestado pelo molusco para investigar seu habitat, sua alimentação e investigar sobre seu processo de inserção.

O espaço não formal é considerado aquele espaço onde pode ocorrer uma prática educativa. Existem dois tipos de espaços não formais: os espaços institucionalizados, composto por uma equipe responsável pelas atividades ali oferecidas; e os espaços não institucionalizados que não dispõem de uma estrutura (JACOBUCCI, 2008, p.56-57). Os espaços não formais são fortes aliados das escolas na formação da cultura científica brasileira, propiciando bases para que os cidadãos possam agir ativamente na sociedade, criticando e transformando sua forma de ver o mundo.

Para Alcântara \& Fachín-Terán (2010, p.03-04) o uso dos espaços não formais como laboratório natural contém inúmeras possibilidades para o Ensino de Ciências, além de proporcionar atividades significativas e prazerosas tanto para os estudantes quanto para professores. A utilização desses elementos contidos na floresta, no ecossistema amazônico, possibilita um desenvolvimento a mais em relação aos conceitos do componente curricular Ciências Naturais.

Mesmo nos espaços formais, como a sala de aula os estudantes podem ser estimulados avaliar algumas situações e expressar suas opiniões a respeito. Em alguns casos não é possível levar os estudantes a determinado local, mas nada impede dos professores buscarem recursos externos ou até então, levar estes recursos para a sala de aula (figura 2).

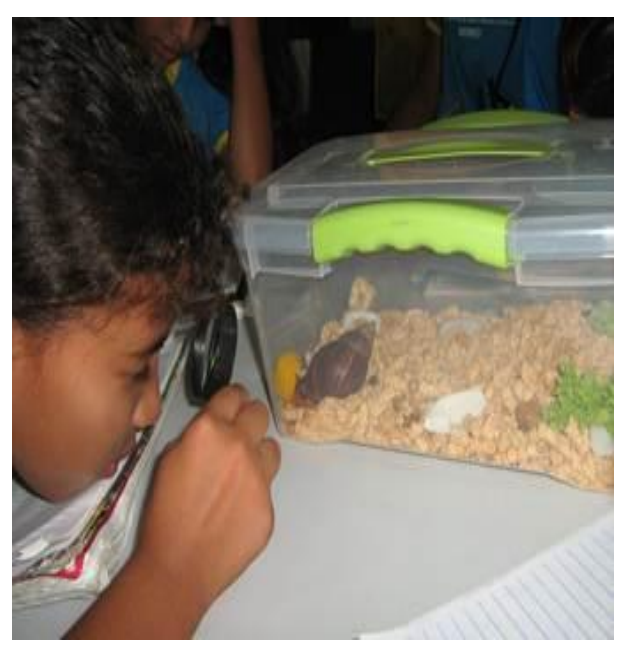

Figura 2: Aluna em sala de aula observando o "Caramujo Africano" com uma lupa. Fonte: QUEIROZ, R.M. 2012. 


\title{
Ensino, Saúde e Ambiente - V 7 (1), Edição Especial, maio de 2014
}

O ambiente formal é o espaço ideal para realizar pesquisas, pois foi projetado para este tipo de atividade. Segundo Capra:

\begin{abstract}
A sala de aulas e o laboratório interno são ambientes ideais para se reduzir a realidade de maneira a enfocar as coisas pequenas. O estudo do lugar, ao contrário, nos permite ampliar o foco para examinar as relações entre as disciplinas e estender a nossa percepção do tempo (2006, p.121).
\end{abstract}

Assim, o verdadeiro papel da educação, seja formal ou não formal, é nos arrancar de um estado de sonambulismo e nos preparar ao encontro com a verdade, seja ela relampejos, amedrontadora, conflitante, irônica ou até aterrorizante. Necessitamos estar preparados a este encontro para compreender que, mesmo no mais profundo silêncio da admiração e da reverência, ao instigarmos e questionarmos nossas profundas e inquestionáveis certezas podemos encontrar respostas satisfatórias e até complexas sobre nós mesmos e a nossa natureza. E a partir disto “[...] nos entregar a um determinado lugar, permanecer ali, questionar a seu respeito, imaginá-lo, tocá-lo, ouvilo e ponderar a respeito" (CAPRA, 2006, p.136).

\section{CONSIDERAÇÕES FINAIS}

Utilizar-se de temáticas que se insiram no contexto de vida do aluno, como o tema "animais exóticos" entre outros temas de relevância social, leva o estudante a despertar um sentimento ecológico de ação em defesa daquele local, entendendo aquilo como de responsabilidade de todos. Isso ajuda na construção de uma sociedade crítica e participativa, reconhecendo os problemas que estão a sua volta e tornando-os responsáveis por suas decisões e ações em defesa de seu espaço e seu bem estar na sua comunidade.

Trabalhar a alfabetização ecológica no Ensino Fundamental leva o estudante a visualizar a complexa rede de inter-relações e a partir daí, entender o funcionamento de tais processos, para depois refletir sobre eles, sensibilizando-se com os problemas ambientais a sua volta. Munir nossos estudantes desta sensibilização ecológica é proporcionar oportunidades de transformá-los de sujeitos passivos de conhecimento a sujeitos ativos na sociedade, conscientes de sua responsabilidade enquanto sujeito ecológico.

A Alfabetização Ecológica é uma alternativa válida para a Amazônia, pois é por meio dela que iremos formar cidadãos participativos, responsáveis e conscientes de que 
as suas decisões sociais, políticas e econômicas, interferem diretamente no seu bem estar ecológico.

\section{REFERÊNCIAS}

ALCÂNTARA, M.I.P.; FACHÍN-TERÁN, A. Elementos da floresta: recursos didáticos para o ensino de ciências na área rural amazônica. Manaus: UEA Edições, 2010, 84p.

CAPRA, F. Alfabetização ecológica: A educação das crianças para um mundo sustentável. Traduzido por Carmen Fisher. São Paulo: Cultrix, 2006. Tradução de Ecological Literacy: Educating our children for a sustainable world.

COELHO, L.M. Informe técnico para o controle do caramujo africano (Achatina fulica, Bowdch 1822) em Goiás. Goiânia: Agencia Rural, 2005. Disponível em:

<http://www.sgc.goias.gov.br/upload/links/arq_253_informecaramujo.pdf>. Acesso em: 15.jun.2011.

ESTON, M.R.; MENEZES, G.V.; ANTUNES, A.Z.; SANTOS, A.S.R.; SANTOS, A.M.R. Espécie invasora em unidade de conservação: Achatina fulica (Bowdich, 1822) no Parque Estadual Carlos Botelho, Sete Barras, SP, Brasil (nota científica). Rev. Inst. Flor., São Paulo, v. 18, n. único, p. 173-179, dez. 2006.

FERRAZ, Joaquim. O escargot: criação e comercialização. São Paulo: Ícone, 1999.

JACOBUCCI, D.F.C. Contribuições dos espaços não-formais de educação para a formação da cultura científica. Em extensão, Uberlândia, V.7, 2008.

MONTEIRO, B. Ideias sobre Alfabetização Ecológica: Ecologia e Amazônia. 2. ed. Belém: Editora Amazônia, 2010.

NAZARENO, L. Estudo de Moluscos: Motivos da incidência de "caramujo africano", Achatina fulica, 2010. Disponível em: 〈http://www.webartigos.com>. Acesso em: 05 jan. 2011.

PAIVA, C.L. Achatina fulica (Moluscos): praga agrícola e ameaça à saúde pública no Brasil. IBAMA, 2004. Disponível em: <http://www.geocities.ws/lagopaiva/ achat_tr.htm>. Acesso em: 16.out.2011.

PIVELLO, V.R. Invasões biológicas no cerrado brasileiro: efeitos da introdução de espécies exóticas sobre a biodiversidade. Departamento de Ecologia Geral; Instituto de Biociências; Universidade de São Paulo; Brasil, 2011. Disponível em:

<http://www.ecologia.info/cerrado.htm>. Acesso em: 16.nov.2011.

RICKLETS, R.E. A economia da natureza. 6. ed. Rio de Janeiro: Guanabara Koogan, 2010.

RODRIGUES, M.V.; JUNIOR, Z.M.F.; MONTEIRO, A.G. Análise do impacto socioambiental do "caramujo africano" no Município de São Gonçalo (RJ). Fórum Ambiental da Alta Paulista, v.3, 2007. Disponível em:

<xa.yimg.com/kq/groups/2106376/.../name/Caramujo+Africano.pdf>. Acesso em: 13 de nov. 2011. 
SAMPAIO, S.M.V.; WORTMANN, M.L.C. Ecoalfabetização: ensinando a ler a natureza. Pesquisa em educação ambiental, v.2, n.2, p.133-152, 2007. Disponível em: <http://www.revistasusp.sibi.usp.br/pdf/pea/ v2n2/08.pdf>. Acesso em: 05 jan. 2011.

SILVA, E.D.; OLIVEIRA, J.M.R.P.B.; NAVARRO, M.F. Achatina fulica: desequilíbrio ecológico, praga agrícola e vetor de doenças. Universidade Federal Rural de Pernambuco, 2007. Disponível em: http://www.eventosufrpe.com.br/jepex2009/cd/resumos/R0752-1.pdf. Acesso em: 30.nov.de 2011.

SOUZA, R.M.; ALVES, Â.G.C.; ALVES, M.S. Conhecimento sobre o molusco gigante Africano Achatina fulica entre estudantes de uma escola pública na Região Metropolitana do Recife. Revista Biotemas. Universidade Federal Rural de Pernambuco/Departamento de Biologia, Recife, 2007.

VASCONCELLOS, M.C.; PILE, E. Ocorrência de Achatina fulica no Vale do Paraíba, Estado do Rio de Janeiro, Brasil. Rev Saúde Pública 2001; 35 (6): 582-4. Disponível em: <http:www.fsp.usp.br/rsp>. Acesso em: 25. nov.2011.

ZANOL, J. FERNANDEZ, M.A.; OLIVEIRA, A.P.M.; RUSSO, C.A.M.; THIENGO, S.C. O Caramujo exótico invasor Achatina fulica (Stylommatophora, Molusca) no Estado do Rio de Janeiro (Brasil): situação atual. Biota Neotrop., vol. 10, n.3, Rio de Janeiro, 2010. Disponível em: <http://www.biotaneotropica.or.br/v10n3/3n/abstract? short-communication+bn006100320 10>. Acesso em: 15.out. 2011. 